\title{
Wireless Technology Leading Innovator- A Case Study of Qualcomm
}

\author{
Sangeetha Prabhu ${ }^{1} \&$ Krishna Prasad K. ${ }^{2}$ \\ ${ }^{1}$ Research Scholar, College of Computer Science and Information Science, Srinivas \\ University, Mangalore, India \\ ${ }^{2}$ College of Computer Science and Information Science, Srinivas University, Mangalore, \\ India \\ E-mail: sangeethaprabhu96@gmail.com
}

Type of the Paper: Research Case Study.

Type of Review: Peer Reviewed.

Indexed In: OpenAIRE.

DOI: http://doi.org/10.5281/zenodo.3545059.

Google Scholar Citation: IJCSBE

How to Cite this Paper:

Prabhu, Sangeetha \& Krishna Prasad, K. (2019). Wireless Technology Leading Innovator- A Case Study of Qualcomm. International Journal of Case Studies in Business, IT, and Education (IJCSBE), 3(2), 68-78. DOI: http://doi.org/10.5281/zenodo.3545059.

International Journal of Case Studies in Business, IT and Education (IJCSBE)

A Refereed International Journal of Srinivas University, India.

IFSIJ Journal Impact Factor for 2019-20= 4.252

(C) With Authors.

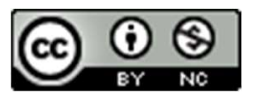

This work is licensed under a Creative Commons Attribution-Non Commercial 4.0 International License subject to proper citation to the publication source of the work.

Disclaimer: The scholarly papers as reviewed and published by the Srinivas Publications (S.P.), India are the views and opinions of their respective authors and are not the views or opinions of the S.P. The S.P. disclaims of any harm or loss caused due to the published content to any party. 


\title{
Wireless Technology Leading Innovator- A Case Study of Qualcomm
}

\author{
Sangeetha Prabhu ${ }^{1} \&$ Krishna Prasad K. ${ }^{2}$ \\ ${ }^{1}$ Research Scholar, College of Computer Science and Information Science, Srinivas \\ University, Mangalore, India \\ ${ }^{2}$ College of Computer Science and Information Science, Srinivas University, Mangalore, \\ India \\ E-mail: sangeethaprabhu96@gmail.com
}

\begin{abstract}
Qualcomm Company was founded in San Diego, California, in July 1985 by Irwin Jacobs and Seven. Qualcomm is a multinational American corporation which seeks to design, create and deliver semiconductor devices and facilities to the industry. Qualcomm originates most of its income from the companies that produce chips and grant patents. Qualcomm has headquarters in nearly 33 nations, with around 35,400 staff worldwide. Qualcomm's quarterly income recorded a 2 percent rise compared to the prior financial process for fiscal year 2018 of US\$ 21.301 billion. Its stocks traded between 51 and 75 dollars per stock; its market capitalism was assessed at 105 billion dollars at the beginning of 2018. The business places 133rd in revenue among the biggest US companies in the Fortune 500 ranking. The firm concentrates on a variety of sectors such as car, schooling, health, networking, Internet forall, portable technology, intelligent housing, intelligent towns, intelligent home applications, and wearables. Qualcomm products include Gobi, IPQ, Snapdragon, Powerline, VIVE Wi-Fi Platforms, Mirasol, Pixtronix, AllPlay, 2net, Brew, HealthyCircles, QChat, QLearn, RaptorQ, Halo and WiPower. Qualcomm products include all types of Gobi, Hy-fi and IPQ products. In the present article, we analyze Qualcomm's business policies by learning different areas of background, economic policy, STEEP evaluation and SWOT analyzes goods.
\end{abstract}

Keywords: Qualcomm, Wireless Technology, Electronics Industry, Case Study, IT Company, Telecommunications Industry.

\section{INTRODUCTION :}

Today, there is a revolution in the world of communication and information transmission, which is wireless. Wireless engineering allows you to communicate over distances between two or more people without cables and wires. This includes wave interactions with Radio Frequencies (RF) and Infra-Red (IR). The Internet affected the way people work, play and communicates. Shopping, research and message are all common uses of PC-based internet applications [1]. In order to ensure cost-effective communications, the internet has rationalized business, personal and monitoring activities. The way people communicate also has an impact on mobile telephones. Cellular use has exploded since culture has been able to talk with each other everywhere at any time [2]. Security and convenience issues are becoming significant motors in their increasing popularity. However, these two functions are combined in the next batch of cell phones. Consumers want to regulate their wireless phones via the Internet. In all kinds of activities, companies want to be mobile. Therefore, companies will flourish that support and standardize the needed wireless equipment and technology. One such business is Qualcomm. The basis for global Wireless Systems is the patented Qualcomm Techniques. Their important research and development actions have enabled them to remain at the top of wireless technology, and a substantial income stream is provided by their wide patent foundation. However, Qualcomm poses difficulties from multiple sides if it is to maintain its leadership position in the sector. These difficulties arise from other producers of chips, alternative wireless norms and telecommunication technologies sponsored by the government. 


\section{International Journal of Case Studies in Business, IT, and Education SRINIVAS (IJCSBE), ISSN: 2581-6942, Vol. 3, No. 2, November 2019.

The Qualcomm, Inc. dedicated to developing and supplying the Code Division Multiple Access (CDMA) electronic cable communications tools and digital technology centre. CDMA is a safe data transmission method for radio frequency. Qualcomm maintains a number of patents which are essential to its core business worldwide and promote various CDMA technological aspects. Prof. Irwin Jacobs \& Andrew Viterbi established the business in 1985 [3]. Its aim is to create a' Quality Communications' company for the public sector, which is why it is called Qualcomm. Qualcomm was built in 1985 with CDMA technology proposed in 1989 for the wireless industry. The present CDMA patents of Qualcomm are more than 400 US patents and more than 900 US patents. About 12 percent of the 550 million clients who use first-and second-century mobile technology use Qualcomm-based CDMA networks. Qualcomm's primary focus is on the global use of its 5th generation wireless model cdma2000. Qualcomm is divided into several branches including Qualcomm CDMA Technologies (QCT) and Qualcomm Wireless Systems (QWS), Qualcomm Technology Licence (QTL). Qualcomm Technology Licenses (QTL) provides producers with CDMA technology with charges and advantages. More than 90 telecommunications appliance manufacturers have been permitted by the company's portfolios of CDMA patents. The world's main manipulator for built-in circuits, systems software and tools for wireless device manufacturers and network equipment is Qualcomm CDMA Technologies (QCT). QCT now manufactures wireless platform circuits through its subsidiary, Snap Track. QCT generates revenue depending on CDMA from sales of products. Qualcomm Wireless Systems (QWS) provides portable communications and logistics leadership services and equipment for the transport sector with OmniTRACS solutions. QWS also creates and builds portals and equipment for the advanced satellite network Globalstar, which offers continuing mobile communication and data services.

\section{AIMS AND OBJECTIVES OF STUDY :}

This is a company case study paper based on the information collected from Qualcomm's business strategies in wireless Technology industry sector. The paper deals with the following aim and objectives [3].

1. To learn the operation level and business level strategies of top multinational IT Company Qualcomm.

2. To know the growth saga of Qualcomm company.

3. To learn about Qualcomm strategy of facing the challenges using their innovative slogan "forward thinking".

4. To know about Qualcomm's strategies of exploring all possibilities as opportunities.

5. To use STEEP and SWOT analysis for the recommendation of Qualcomm's future strategies for accelerated success.

3. JOURNEY OF SUCCESS :

- Qualcomm was established in 1985 in San Diego and is a leading worldwide wireless chip designer for $3 \mathrm{G}, 4 \mathrm{G}$ and $5 \mathrm{G}$ devices.

- Qualcomm can now almost solely focus on its activity by resolving the licensing dispute with Apple.

- The 5G generation is now under implementation, which means that profits and cash flows can be expected to increase in the foreseeable future.

- Qualcomm's valuation is favourable compared to the peer group and, despite the share prices rally owing to the Apple sale, is essentially undervalued.

- Moreover, a pending share buyback scheme of about $\$ 7.8$ billion and a current dividend of more than $3 \%$ also speaks in the future of an appealing shareholder value.

4. QUALCOMM'S INNOVATIVE SLOGAN "FORWARD THINKING" : 


\section{International Journal of Case Studies in Business, IT, and Education SRINIVAS (IJCSBE), ISSN: 2581-6942, Vol. 3, No. 2, November 2019. \\ PUBLICATION}

The slogan is a commemorative sentence, used for repeated expressions of concept or reasons in a tribe, politics, commerce, religion or other context to convince members of the audience or a more specified target group. The Qualcomm Wireless Reach ${ }^{\mathrm{TM}}$ project introduces sophisticated wireless systems to underserved societies around the globe with a view to enhancing financial and social development. The slogan or the business slogan of Qualcomm's publicity is "Forward Thinking"[4]. Mission statements and vision statements are written for corporate clients and employees. A Statement of a Mission may be described as a phrase or a brief paragraph published by a company or a corporation reflecting its key objective, identity and values and business principles. A sentence or brief paragraph is the definition of a Vision Statement which gives a wide inspirational future picture. Qualcomm Mission Statement is "Future Perspectives-We can see the future from the high heights of our dreams. Your vision of what may take place tomorrow inspires us every day. We aim every day to make this view the foundation of a new wireless world. So while nobody is sure what is going to be the future, we have a pretty good idea.

The old logo was a sad thing, with far too many inconsistencies to remove the "mm" ligature [4]. The "Q" was too audacious, the "u" was too carved and condensed, and the "m" was the only rounded corner pieces. This new logo retains the essence of the old one whose share of equity is strange and good but rewrites it fairly perfectly. The space in each letter matches, the proper capitalization of the word is easier to read and the mm part of the word mark is now far more integrated. It is still the only uppercase / unicase letters, but it is powerful and unified from the visual perspective. The " $\mathrm{m}$ " case and the redundancy were definitely explored but I like that they stuck with the transistors queue looking diagonal "ms." I'm sure that they stuck with the "m"s. The subtle shading version of the rendering provides the logo a kind of interesting softness.

5. FINANCIALS :

A comparative summary of Qualcomm's Financials for last four years 2015 to 2018 is given in table 1 [3-9] and graphically represented in figure 1.

Table 1: Last four years Financial Statement

\begin{tabular}{|l|l|l|l|l|}
\hline Revenue & $\mathbf{2 0 1 5}$ & $\mathbf{2 0 1 6}$ & $\mathbf{2 0 1 7}$ & $\mathbf{2 0 1 8}$ \\
\hline Total revenue & $2,52,81,000$ & $2,35,54,000$ & $2,22,91,000$ & $2,27,32,000$ \\
\hline Cost of revenue & $1,01,06,000$ & $93,15,000$ & $93,55,000$ & $97,95,000$ \\
\hline Gross profit & $\mathbf{1 , 5 1 , 7 5 , 0 0 0}$ & $\mathbf{1 , 4 2 , 3 9 , 0 0 0}$ & $\mathbf{1 , 2 9 , 3 6 , 0 0 0}$ & $\mathbf{1 , 2 9 , 3 7 , 0 0 0}$ \\
\hline Operating expenses & $54,76,000$ & $51,41,000$ & $54,35,000$ & $56,19,000$ \\
\hline Research development & $22,72,000$ & $22,86,000$ & $21,57,000$ & $21,05,000$ \\
\hline Selling general and administrative & - & - & - \\
\hline Non recurring & $-18,000$ & $-1,80,000$ & -18000 & -18000 \\
\hline Others & $1,78,54,000$ & $1,67,42,000$ & $1,69,47,000$ & $1,75,01,000$ \\
\hline Total operating expenses & $\mathbf{7 4 , 2 7 , 0 0 0}$ & $\mathbf{6 8 , 1 2 , 0 0 0}$ & $\mathbf{5 3 , 4 4 , 0 0 0}$ & $\mathbf{5 2 , 3 1 , 0 0 0}$ \\
\hline Operating income or loss & \multicolumn{5}{|l|}{} \\
\hline Income from continuing operations & $-9,40,000$ & 21,000 & $-23,24,000$ & $-47,18,000$ \\
\hline Total other income/ expenses net & $74,27,000$ & $68,12,000$ & $53,44,000$ & $52,31,000$ \\
\hline Earnings before interest and taxes & $-1,04,000$ & $-2,97,000$ & $-4,94,000$ & $-7,68,000$ \\
\hline Interest expense & $64,87,000$ & $68,33,000$ & $30,20,000$ & $5,31,000$ \\
\hline Income before tax & $12,19,000$ & $11,31,000$ & $5,55,000$ & $53,77,000$ \\
\hline Income tax expense & -7000 & $-10,000$ & - & - \\
\hline Minority interest & $\mathbf{5 2 , 6 8 , 0 0 0}$ & $\mathbf{5 7 , 0 2 , 0 0 0}$ & $\mathbf{2 4 , 6 5 , 0 0 0}$ & $\mathbf{- 4 8 , 6 4 , 0 0 0}$ \\
\hline Net income from continuing Ops & \multicolumn{2}{|l}{} \\
\hline Net income & &
\end{tabular}




\begin{tabular}{|l|l|l|l|l|}
\hline Net income & $52,71,000$ & $57,05,000$ & $24,66,000$ & $-48,64,000$ \\
\hline $\begin{array}{l}\text { Preferred stock and other } \\
\text { adjustments }\end{array}$ & - & - & - & - \\
\hline Net income applicable to shares & $\mathbf{5 2 , 7 1 , 0 0 0}$ & $\mathbf{5 7 , 0 5 , 0 0 0}$ & $\mathbf{2 4 , 6 6 , 0 0 0}$ & $\mathbf{- 4 8 , 6 4 , 0 0 0}$ \\
\hline
\end{tabular}

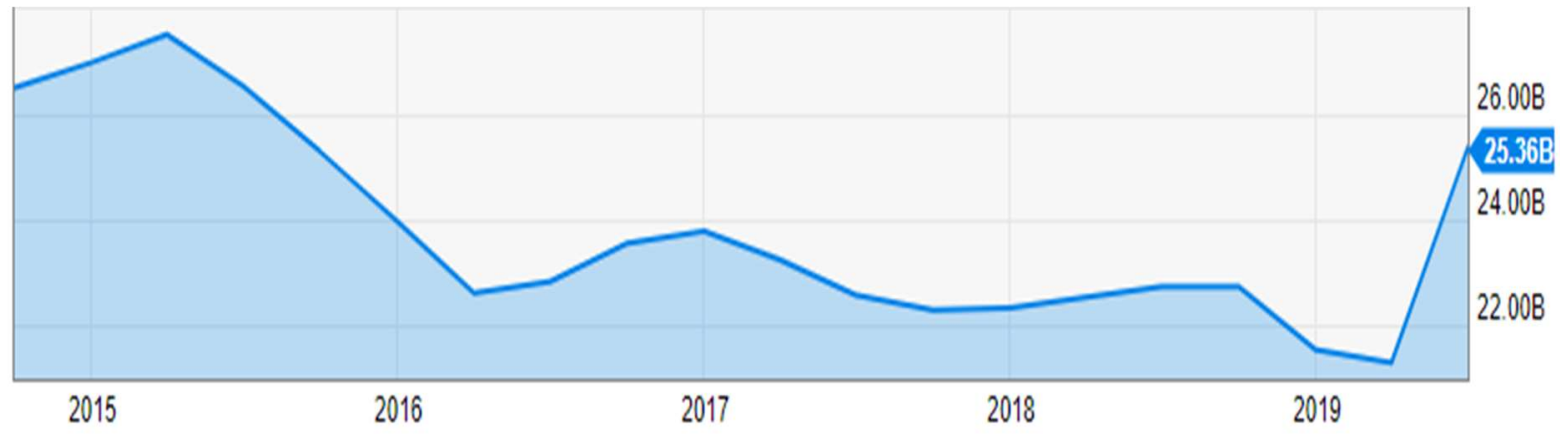

Fig. 1: Qualcomm's last four years revenue growth

\section{SUSTAINABILITY THROUGH GREEN STRATEGY :}

Qualcomm is devoted to the sustainable use of wireless systems worldwide. Our strategy is sustainable by integrating financial, social and company governance issues into our business model, especially in relation to our key effect fields, such as the workers, supply chain and the local community. From their daily operations to their leadership and governance committee, they have integrated sustainability across your business. Sustainability influences their strategic choices, their product design and their workers' everyday thinking and behaviour.

The sustainable development task of Qualcomm:

- Develop technologies that transform the environment favourably

- operate at the greatest norms of ethics

- Be an excellent location for job

- Be excellent company individuals everywhere we operate

- Keep adding importance to stockholders

6.1 FRAMEWORK 'S PILLARS :

The sustainability obligations of Qualcomm are in particular [3-9], [14]:

A. GOVERNANCE

- During all activities and relationships with the staking parties the company shows responsibility, honesty, transparency and ethical company methods.

- The company constantly improving its sustainable management, including better transparency, reporting, communications and measurable objectives.

- Improve knowledge and exposure within the company and with contractual providers and main suppliers of human rights values.

- Reviews the corporate management values and procedures on a regular basis in order to guarantee that the company serve the greatest interests of the stockholders and others.

- All employees are required to revise and recognize the company Code, Foreign and corrupt laws and anti-corruption policies.

\section{B. CHAIN OF PRODUCTS AND SUPPLIES}

- The company develop technologies to empower individuals around the globe and improve quality of lives.

- Company create products that take its economic and social effect into consideration.

- By applying and allowing accountable privacy and data security methods, copany create confidence in the usage of wireless systems.

- The company allows semiconductor providers to behave in conformity with the Code of Conduct of the Coalition for Electronic Industry Citizenship and expect them to acquire products from 
environmental and socially responsible sources, including conflict free sources within and around the Democratic Republic of the Congo (DRC).

C. WORKPLACE FACILITIES AND STAFF

- The goal is to boost diversity at all stages of the company and to continually develop and implement measures to tackle our talent pipeline gaps.

- The company pledge to reward its entire staff fairly and justly.

- Company provide possibilities for all our staff for practice, development and promotion and encourage well-being, work / life equilibrium and general health for staff.

- Employees are secure and healthy in company surroundings.

- It uses approaches to handle water use responsibly, to lower greenhouse gas emissions, to improve power effectiveness and the use of equipment, to decrease waste and to decrease hazardous substances throughout its activities.

D. SOCIETY

- Company develops strategic connections with a wide variety of local organizations and programmes, which develop and strengthen communities around the world.

- Sustainable wireless initiatives, focusing on schooling, business growth, health care, the climate and public safety, enhance economic and social development and reinforce wireless technology.

- These programs promote needs in line with the development of Qualcomm and boost the volunteering of employees through creative programs with global local NGOs. The company committed to enhancing education in science, technology and engineering at all levels.

\section{QUALCOMM BUSINESS STRATEGIES :}

You could just display a Qualcomm module on your desktop or on your mobile device. This is the major LTE chip maker and its products are available in nearly every mobile device brand. Only two of the biggest names with Qualcomm parts are Apple and Samsung[12]. Its revenue is generated by the manufacturing and selling of these chips and the lending to other producers of the technology. In other words, comparing Qualcomm with a customer toll company's business model is simple. You are the only person in your business to do that, so you can put your own cost and get individuals to choose whether to pay. In the past 20 years, this business model has generated huge operating margins and incredible development.

Qualcomm is entitled to add its chips to $3 \mathrm{G}$ and $4 \mathrm{G}$ mobile devices in China with suppliers. The only issue is a continuing inquiry into the company structure of Qualcomm-the Chinese edition of the SEC, the NDRC. There is a matter of the quantity of lease charges and use privileges paid by the business. The inquiry resulted in some of the lower contracting organisations underreporting or failing the amount of units transferred for Qualcomm. The business has therefore changed its Wall Street selling figures. The ultimate domino in this adverse cascade is that shareholders have significantly reduced stock value. For Qualcomm there is also a prospective issue in China: the NDRC might start regulating its contract charges in China. China is the fastest increasing industry for intelligent devices and Qualcomm is the leading chip maker [13]. Short-term income has already been impacted. The long-term prospects of Qualcomm in China might be influenced by its model of company.

The invention is a key component of the business model of Qualcomm: the Qualcomm business model shows some sustainability, in particular as far as research and development is concerned. It is not just profitability, it thinks. Qualcomm thinks it must be a goal of creation, for the creation is at the heart of human development. It could be asserted that this philosophy inspires a portable revolution. Qualcomm has created some wonderful stuff but has also motivated others to invent great stuff and use chips as their basis [14]. "Inspire" is the keyword. The ultimate objective is to simplify and improve the connection of all parties. The business model of Qualcomm is as simple as feasible in some ways. They found an issue, solved it and continued to sell it.

\section{PRODUCTS :}

- Semiconductors [15]: The quality of the SnapDragon brand in ARM is CDMA, LTE, UMTS and $5 \mathrm{G}$ chipset and SOC products. These chipsets are for mobile phones, like Kyocera, HTC, Motorola Mobility, Sharp, Sanjo, Sony, Xiaomi and Samsung. They can be bought for mobile phones 
included. While a semi conductor "fables" company means that Qualcomm does not take part in the actual fabrication technology, there are a large number of devices and devices powered by worldwide CDMA and UMTS processors. After Micron Technology, Intel, SK Hynix and Samsung Electronic devices, Qualcomm is one of the leading semiconductor manufacturers since 2017. Also under the names CSR, QCA and QCC, Qualcomm generates multiple low-power SoCs.

- Tracking devices [15]: As of April 2012, roughly 1.5 million unit installations were deliverable into companies in 39 countries on 4 occasions. The OmniTRACS system is a two-way satellite communication and geo-location vehicle system intended for the over-the-road industry in shipping and transportation servicer online

- Server processors [15]: In 2015, Qualcomm declared the introduction of its Centric chipsets depending on the Falkor CPU in the company's server industry. Development was launched in late 2016 with accessibility due for the same year.

- Satellite phones [15]: Qualcomm produces some of the phones on the network of Globalstar.

- MediaFLO [15]: Qualcomm inventor of the OFDM derived MediaFLO scheme that transmits 12$15 \mathrm{TV}$ stations within a range of $6 \mathrm{MHz}$. Qualcomm uniform TIA's reduced levels and produces chips and software to bring this cellular television capacity.

- QChat [15]: QChat is a 2-way voice communication push-to-tabbing mobile / data system. The initial push-to-talk technology from Nextel is operated on the iDen network, but the Qchat push-totalk from Qualcomm works on the mobile broadband network of Evolution-Data Optimized Revision A (Evolution-DO Rev. A). In June 2008, Sprint-Nextel first published Qchat telephones. The handsets are both marketed under the Nextel name, iDen and Qchat. On 29 November 2009 the company published a declaration on PhoneNews.com that the product development roadmap does not contain fresh QChat devices, but that its current QChat users will proceed to support it.

- Qualcomm Gobi/Snapdragon X-Series [15]: Qualcomm Gobi is a portable high band chipset primarily used for portable data networking, which is also used on a few smart phones in companies. The technology is currently a $3 \mathrm{G}$ system that can operate on GSM and EV-DO Rev. the Gobi Chipset can add a certain airline picture to make it specifically intended for the network of that airline. As GSM and CDMA differentiate considerably and Gobi phones can move to the same silicone between the two, their method is regarded as creative. Gobi Technology is best suited for big business customers where one mobile operator cannot supply all of their cellular modem requirements, as there is no single airline providing the same amount of delivery wherever it requires the product. The Gobi-Solution enables the IT department to implement a single module on its laptop designs that can be installed just like a phone attached to the vehicle they want to use in this region. The CDMA network or GSM network of your selection can be equipped with precisely the same hardware in the United States. For GSM customers who move from the USA the Gobi-Solution can be employed by shifting the SIM and airline picture from the phones to a local supplier rather than incurring roaming costs to prevent international roaming charges. The client has to have distinct cable records with each supplier in both situations that they want to use natively. The airline picture is usually loaded into NVRAM for 20 seconds and re-set and returned internet. The next Gobi 3000 hardware overhaul promotes the HSPA+ application. The model is distinct for Gobi 3000. It is a form of mention that can be licensed and produced by OEMs with their own Gobi 3000 compatible modules. Qualcomm has no Gobi 3000 silicone on sale. The reference architecture enables OEMs to concentrate on developments on the mobile broadband system rather than to bind down with low level RF implementation, using the same hardware and software components as the boilerboard based on the OEM chips. Gobi applications have now natively endorsed LTE. In December 2014, in the Snapdragon X Series, Qualcomm rebroken its Gobi modem products.

- Mirasol displays [15]: The first and only pivotal screens depending on IMOD technology in the world are Mirasol screens. The mirasol screens from Qualcomm use environmental energy as their colour input and produce almost no energy when the picture remains untouched. This leads to a very small energy view, even under immediate sunlight. The answer is noticeable.

- HALO [15]: A norm for wireless charging of comparatively elevated efficiency cars by resonant inductive connections. developed in Auckland University over 10 years of studies. 


\section{SOFTWARE'S :}

- Operating system [15]: BREW is a proprietary cellular application platform (the Binary Runtime Environment for Wireless). BREW is designed to reject unregistered applications on the platform. For signing an application, the developer has to pay the National Software Testing Laboratories (NSTL) a test fee which is subsequently permitted or rejected the application. This allows carriers to maintain control of the applications running on phones of their customers. BitPim is a common open source program that uses cable or Bluetooth with Qualcomm MSMs to access a built-in mobile file system. Java ME is also used for signing systems in AppleiOS and carriers and OEMs are often required to sign them.

- Speech codec [15]: Qualcomm created an audio codec called PureVoice for voice that, in addition to using it on cell phones, is also licensed for use with the popular Tencent QQ software for Chinese instant messaging.

- FEC codec [15]: Qualcomm created the recent iteration of Raptor Q codes after acquiring Fremontbased Digital Fountain in 2009.

- Eudora client [15]: Eudora was originally created by Qualcomm and circulated, purchased by its writer Steve Dorner in 1991. On 1 May 2007, Qualcomm stopped selling Eudora. Qualcomm has committed them to cooperating with Mozilla developers to produce a Eudora-style version of the so-called Project Penelope, which was subsequently re-named Eudora OSE and which was declared dead by the Mozilla project on 28 June 2013.

- Eudora servers [15]: Qualcomm has created and marketed e-mail applications on several systems, including Windows Mail and Macintosh's EIMS. These products are not sold by Qualcomm any more. The famous open-source qupopper for Linux and Unix is still maintained and distributed by Qualcomm.

- aptX Bluetooth codec [15]: Qualcomm has created a Bluetooth class of proprietary compression algorithms for audio codecs marked with aptX.

- Technology of cVcTM Noise Cancelation [15]: Qualcomm created the class of proprietary cVcTM cancellation noise control systems.

\section{SWOT AND SWEET ANALYSIS :}

It seeks at designing, developing semiconductors and business equipment and facilities for wireless telecommunication. The firm focuses on different sectors, including automotive, education, medical care, Internet of All, mobile computing, intelligent household, intelligent cities, intelligent housing, and wearables. Qualcomm is an American-based wireless company. It seeks at developing, developing semiconductors and marketing wireless equipment and facilities. It focuses on different sectors, such as manufacturing, training, healthcare, networking, the Everything Internet, mobile computing, intelligent homes, intelligent cities, intelligent homes, and wearalbles.

The SWOT analysis shows that [3-9]:

\section{A. STRENGTHS OF QUALCOMM:}

- In North America, CDMA is extremely invasive.

- Due to their violent security for intellectual estate, their capacity to safeguard patents is a significant competence.

- Qualcomm offers funds to further expand research and advancement in order to deliver consistent revenues and profitability and growth.

B. STRENGTHS OF COMPETITORS:

- Cross licenses for new and competitive techniques, available free of royalties.

- The operational history and business existence have been created.

- More brand awareness.

- Longer access to the client base.

- Increased financial, sales, marketing, manufacturing, production and technology assets;

C. QUALCOMM'S WEAKNESSES:

- The revenues of Qualcomm are due to three Korean clients, losing 39 percent to any of QCT's significant clients. The revenues of Global Star accounted for 30\% of the QWS segment revenues. 
- A restricted proportion of third-party producers are dependent on the production and testing of goods. Any disruption to the operation of these third parties might damage service commitments, as described in Porter's five forces.

- Qualcomm provides CDMA network financing to its licensees. If these customers do not recognize their debts, Qualcomm's economic situation could be affected.

- Global star has elevated cost of facilities, which may adversely affect item development

D. WEAKNESSES OF RIVALS:

- Competitors ' network technology focuses mainly on GSM. If they do not have new technology to meet $3 \mathrm{G}$ networks, their development can be limited.

- Competition in North America has a restricted business share.

E. QUALCOMM'S OPPORTUNITIES:

- Opportunities for Qualcomm: Third generation wireless communication requires of the sector.

- Emerging economies in Asia, especially China and India. The total population of both these economies is about 2.2 billion or $40 \%$ of the world's inhabitants.

- Spinco will contribute to all-embracing its permits.

- CDMA is expected to contribute to significant development in revenues.

F. COMPETITORS' OPPORTUNITIES:

- Wireless communication needs of the industry for third generation.

- Asian emerging markets, China and India in particular. Both of these markets have a combined population of about 2.2 billion or $40 \%$ of the world's population.

- Open the door to new products can be adopted for alternative standards.

G. COMMON THREATS BOTH FOR AND AGAINST THE QUALCOMM:

- Rapid changes in technology could make current goods outdated.

- A deterioration of the execution of a fresh item could affect business share and income.

- Poor economic health will have a negative impact on significant clients ' profitability.

- International overseas exchange instability and fluctuation can hamper development and revenues.

- The acceptance of network technology of third generation.

- Health hazards: In the medical sector, several White Papers debating whether wireless emissions can be associated with various health problems, such as cancer, have been released. This may discourage the consumers of this item, which affects the sale of licenses for technology.

The assessment by STEEP shows [3-9]:

- Situation: Wireless interaction and robotics are the early phase of the product life cycle. During the next century, many fresh technology types could be developed and fresh companies and partnerships could be formed. Satellite communications are developing and can provide a feasible solution to land-based wireless systems.

- Technology: At the beginning of the design phase. New technology is developing quickly and the mental benefit to Qualcomm is to achieve its economic goals.

- Economic: The scenario is unsure at the moment. In the financial year 2000, Qualcommrelies on $47 \%$ of its global clients [19]. In an abrupt foreign economy, its revenue and earnings are being adjusted. In addition, their income is adversely impacted when customer expenditure continues to stagnate in the US.

- Political: As mentioned, if the policy environment shifts in Korea or China, the effects of Qualcomm are also immediate and $47 \%$ of revenues depend on global customers.

\section{CONCLUSION :}

Qualcomm has been a technology innovator for years that monetizes R\&D on two sides: marketing smart phones as well as other smart devices for sensors, and another is awarding licenses for its patent portfolio. The licensing company has traditionally generated nearly two-thirds of Qualcomm's profits while investing much less than the chip industry. Nothing undergoes forever-no patents, certainly. Qualcomm has greatly enjoyed linking the chip business and also, it's patent portfolio smartly, but it has finished the jig then it will have to adapt to its new paradigm. The industry cannot keep its system long in the soil with an extraordinarily pivotal court case arriving at its head over the expected to come several weeks. Investors will soon have to confront the fact that the long-standing business model of 


\section{International Journal of Case Studies in Business, IT, and Education SRINIVAS (IJCSBE), ISSN: 2581-6942, Vol. 3, No. 2, November 2019. PUBLICATION}

Qualcomm is likely to follow its CDMA technology-a contemporary relic that lingers other than his glory as a shadow of his former selves. In this paper we discussed the corporate policy, finance, corporate practices and foundations in order to achieve the objectives of IT Company Qualcomm. The advantages and disadvantages of these company processes and strategies are also examined in order to differentiate their effectiveness within the company. Qualcomm provides wireless technology for transformation and license patents. Here we discussed about the products and software's which are manufactured by the company and also detailed information was provided on Qualcomm's business strategies and the effect of these policies on development.

\section{REFERENCES :}

[1] Bhushan, N., Li, J., Malladi, D., Gilmore, R., Brenner, D., Damnjanovic, A. \& Geirhofer, S. (2014). Network densification: the dominant theme for wireless evolution into 5G. IEEE Communications Magazine, 52(2), 82-89.

[2] Levin, M. S. (2017). Towards combinatorial modeling of wireless technology generations. arXiv preprint arXiv:1708.08996.

[3] Irwin Mark Jacobs, \& Richard SULPIZIO (1999). Big ideas enabled by CDMA. Retrieved from https://investor.Qualcomm.com/sec-filings/annual-reportson 14/08/2019.

[4] Steve Mollenkopf (2016). QUALCOMM Incorporated Annual report 2016. Retrieved from https://investor.Qualcomm.com/sec-filings/annual-reportson 14/08/2019.

[5] George S. Davis (2017). QUALCOMM INC/DE Annual report 2017. Retrieved from https://investor.Qualcomm.com/sec-filings/annual-reportson 14/08/2019.

[6] George S. Davis (2015). QUALCOMM INC/DE Annual report 2015. Retrieved from https://investor.Qualcomm.com/sec-filings/annual-reportson 14/08/2019.

[7] George S. Davis (2014). QUALCOMM INC/DE Annual report 2014. Retrieved from https://investor.Qualcomm.com/sec-filings/annual-reportson 14/08/2019.

[8] George S. Davis (2013). QUALCOMM INC/DE Annual report 2013. Retrieved from https://investor.Qualcomm.com/sec-filings/annual-reportson 14/08/2019.

[9] William F. Davidson, Jr. (2005). QUALCOMM Annual report 2005. Retrieved from https://investor.Qualcomm.com/sec-filings/annual-reportson 14/08/2019.

[10] Grajski, K. A., \& Kirk, E. (2003). Towards a mobile multimedia age-Location-based services: A case study. Wireless Personal Communications, 26(2-3), 105-116.

[11] Gandal, N., Salant, D., \& Waverman, L. (2003). Standards in wireless telephone networks. Telecommunications Policy, 27(5-6), 325-332.

[12] Kimmel, L. (2018). Broadcom's Proposed Acquisition of Qualcomm: A Bad Deal for Innovation and Consumers. Morning Consult, Forthcoming.

[13] Hou, L. (2016). Qualcomm: How China has Invalidated Traditional Business Models on Standard Essential Patents. Journal of European Competition Law \& Practice, 7(10), 686-689.

[14] Wright, J. D., Ginsburg, D. H., \& Edwards, L. (2019). Section 2 Mangled: FTC v. Qualcomm on the Duty to Deal, Price Squeezes, and Exclusive Dealing. Qualcomm on the Duty t*o Deal, Price Squeezes, and Exclusive Dealing (August 7, 2019). George Mason Law \& Economics Research Paper, (19-21).

[15] Qualcomm (2019), Wikipedia. https://en.wikipedia.org/wiki/Qualcommon 14/08/2019.

Retrieved from

[16] Adeleke, M. J., Grebe, A., Kretschmer, M., \& Moedeker, J. (2017, December). Spectrum Utilization Assessment of Wi-Fi Network Using Qualcomm/Atheros 802.11 Wireless Chipset. In International Conference on e-Infrastructure and e-Services for Developing Countries (pp. 180-191). Springer, Cham. 
[17] Adami, A., Burget, L., Dupont, S., Garudadri, H., Grezl, F., Hermansky, H., \& Sivadas, S. (2002). Qualcomm-icsi-ogi features for asr. In Seventh International Conference on Spoken Language Processing.

[18] Kim, S. Y. (2012). The politics of technological upgrading in South Korea: how government and business challenged the might of qualcomm. New Political Economy, 17(3), 293-312.

[19] Lee, J. S. (1994). Overview of the technical basis of Qualcomm's CDMA cellular telephone system design: a view of North American TIA/EIA IS-95. In Proceedings of ICCS'94 (Vol. 2, pp. 353-358). IEEE.

[20] Salmasi, A., \& Gilhousen, K. S. (1991, May). On the system design aspects of code division multiple access (CDMA) applied to digital cellular and personal communications networks. In [1991 Proceedings] 41st IEEE Vehicular Technology Conference (pp. 57-62). IEEE.

[21] Farrokhi, F. R., Lozano, A., Foschini, G. J., \& Valenzuela, R. A. (2002). Spectral efficiency of FDMA/TDMA wireless systems with transmit and receive antenna arrays. IEEE Transactions on Wireless Communications, 1(4), 591-599.

[22] Zhang, N., \& Brodersen, R. W. (2000). Architectural evaluation of flexible digital signal processing for wireless receivers. In Conference Record of the Thirty-Fourth Asilomar Conference on Signals, Systems and Computers (Cat. No. 00CH37154) (Vol. 1, pp. 78-83). IEEE.

[23] Sarraf, S. (2019). 5G Emerging Technology and Affected Industries: Quick Survey. American Scientific Research Journal for Engineering, Technology, and Sciences (ASRJETS), 55(1), 7582.

[24] Webb, W. (2019). Wireless Comms. Beyond 2020. In Industry 4.0 and Engineering for a Sustainable Future (pp. 49-64). Springer, Cham.

[25] Verma, L., \& Lalwani, M. (2019). Digital Transformation: Impact of 5G Technology in Supply Chain Industry. In Technology Optimization and Change Management for Successful Digital Supply Chains (pp. 256-274). IGI Global.

[26] Beunza Ibanez, D., Harmon, D., Jarzabkowski, P., Marti, E., \& Scherer, A. G. (2019). Finance in Organization Theory: State of the Art and Future Research Agenda. In Academy of Management Proceedings (Vol. 1, No. 1, p. 12370). Briarcliff Manor, NY 10510: Academy of Management.

$* * * * * * * * * * * *$ 